\title{
Associations Between Physical Fitness, Objectively Measured Physical Activity and Academic Performance
}

\author{
Saša Đurić ${ }^{1}$, Špela Bogataj ${ }^{1,2 *}$, Vinko Zovko ${ }^{3}$ and Vedrana Sember ${ }^{1}$ \\ ${ }^{1}$ Faculty of Sports, University of Ljubljana, Ljubljana, Slovenia, ${ }^{2}$ Department of Nephrology, University Medical Centre \\ Ljubljana, Ljubljana, Slovenia, ${ }^{3}$ School of Economics and Business, University of Ljubljana, Ljubljana, Slovenia
}

\section{OPEN ACCESS}

Edited by:

Radenko M. Matic

University of Novi Sad, Serbia

Reviewed by:

Bojan Masanovic,

University of Montenegro, Montenegro Aleksandra Aleksić Veljković,

University of Nis, Serbia Maja Horvatin,

University of Zagreb, Croatia

*Correspondence:

Špela Bogataj

spela.bogataj@kclj.si

Specialty section: This article was submitted to

Children and Health,

a section of the journal

Frontiers in Public Health

Received: 17 September 2021 Accepted: 01 November 2021 Published: 09 December 2021

Citation:

Đurić S, Bogataj Š, Zovko V and Sember V (2021) Associations Between Physical Fitness, Objectively Measured Physical Activity and Academic Performance. Front. Public Health 9:778837. doi: 10.3389/fpubh.2021.778837
There is evidence that physical activity (PA) can improve the academic performance. We recruited healthy adolescent girls, aged 11-12 years, and measured their PA with the accelerometer ActiGraph GT3X for the consecutive 5 days. Physical fitness (PF) was measured with eight motoric tests and three anthropometry measures. Academic performance (AP) was assessed for the six academic narrated school subjects. The results revealed that the girls were more physically active during the week days and less active at weekend (557 vs. 516 counts/min). Physical education grade shows the highest overall correlations with the results of the PF test battery $(r=0.53-0.95, p<0.01)$. Nevertheless, correlations surprisingly decrease for the combined daily PA $(r=0.45)$, especially the weekend PA ( $r=0.28)$. Grade point average and PF correlated moderately $(r=0.43-0.64)$, while they were moderate to high for PA $(r=0.59-0.87)$. Many questions arose after the completion of the present study and several new topics opened up, such as the question of how parental education affects the duration of PA and AP of the children and the influence of the place of residence AP of the children.

Keywords: physical activity, academic performance, girls, physical fitness, mathematic grade, grade point average

\section{INTRODUCTION}

Physical activity (PA) is defined as any bodily movement produced by the skeletal muscles and resulting in energy expenditure (1) that is greater than at rest (2). It has a positive effect on the physical and mental well-being and the general quality of life (3-6). In addition, the physical and psychological benefits of PA are widely acknowledged $(7,8)$, while there is not abundant evidence about direct effects of PA on cognition (9). Therefore, researching the influence of PA on the academic performance (AP) is a current research topic of great interest around the world due to increasing evidence about the positive effect of PA on cognitive functioning (10).

The studies on the cognitive benefits focus mainly on the development of learning skills and AP in relation to physical education (PE) and PA (11-13) in children and adolescents (14), which has been developed on the fact that PA increases oxygen saturation $(15)$ and angiogenesis $(16,17)$ in brain areas responsible for the performance of tasks. Findings from the recent systematic reviews and meta analyses have shown that higher levels of PA are associated with the higher levels of AP $(9,18-20)$. Not all of these reviews took into account, the methodological quality of the studies included and examined only the AP of the pupils, who were usually assessed by evaluating their knowledge and scholastic aptitude in various subjects, with mathematics and literacy being 
the most important (21). Recent studies have mostly investigated the impact of classroom breaks and physically active learning (22-24). That is problematic due to different underlying mechanisms of change, such as blood-flow, brain-derived neurotrophic factors, and plasma catecholamines (17, 19, 25-27).

The cognitive and academic training of children is to a large extent a task entrusted to the education system. To improve AP, teaching time for the core academic subjects is extended and protected, often at the expense of time spent in PE and other areas of the curriculum (19). Nevertheless, the fact that Slovenia has one of the best curricula for PE in the world $(28,29)$, such a trend could potentially also hurt the Slovenian educational system. To our knowledge, PA in Slovenia was usually estimated using questionnaires $(30,31)$, which are less reliable (32) than objective methods. Only recently have Slovenian researchers begun acquiring such data in a more objective way: with accelerometers $(33,34)$. Nevertheless, to the best of our knowledge, there is no evidence of a study dealing with the relationship between AP and objectively measured PA.

The aim of the present study was to investigate the relationship between physical fitness (PF), objectively measured PA of Slovenian girls and their AP, which was based on the grade point average (GPA) and separate grades of the four specific subjects.

\section{MATERIALS AND METHODS}

\section{Participants}

We recruited 20 primary school girls, aged 11-12 years (height $161.3 \pm 0.52 \mathrm{~cm}$; weight $52.1 \pm 0.9 \mathrm{~kg}$; triceps skinfold $16.3 \pm$ $6.7 \mathrm{~mm}$ ). Four of them were excluded from the study regarding the rule 70/80 (35) and illness. The study was conducted in accordance with the Declaration of Helsinki and all participants signed informed consent approved by the National Medical Ethics Committee (ID 138/05/13).

\section{Procedures}

\section{Physical Fitness}

The body height was measured when the subjects were in sportswear and did not wear shoes, using a mechanical stadiometer platform (Seca $囚$ 213, Hamburg, Germany) with a small technical error of measurement (TEM $=0.019 \%$ ).

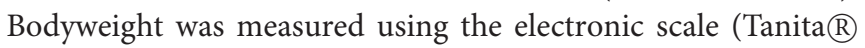
BC544, Tokyo, Japan; TEM $=0.510 \%$ ). The skinfold of the triceps was measured halfway between the acromion process and the olecranon process with the Harpenden skinfold caliper.

Physical abilities were determined using the SLOfit test battery. All tests have been evaluated on a sample of Slovenian population and have appropriate dimensional characteristics and are suitable for the use. For every PF indicator, one test was used: sit-ups, standing long jump, sit and reach, running $60 \mathrm{~m}$ and $600 \mathrm{~m}$.

\section{Physical Activity}

In order to objectively assess the level of PA, participants have worn accelerometer Actigraph GT3X (Actigraph LLC, Pensacola, FL) for 5 days, comprising of three school days
(Wednesday, Thursday, and Friday) and two weekend days (Saturday and Sunday). Counts signal was sampled in the 15-s epochs in the present study. Data of sleep and awake time were logical and coincided with diary logs and covered school time, extracurricular activities, after-school time and evenings (daytime, excluding mornings, and sleep time). If any accelerometer count was $>16,000$ counts/min, these were removed, because it is assumed to be beyond biologically plausible range (36). Likewise, if the device recorded the number of counts $\geq 0$, which was constant for $10 \mathrm{~min}$ or more, these data were also removed, because it is assumed to be accelerometer malfunction (37). Furthermore, the wear time was calculated regarding the rule 70/80 (38). Wear time was defined from 7:00 to 21:30 (870 $\mathrm{min}$ ), hence accepted wear time was $609 \mathrm{~min}$ or more per day. The sequences of 20 consecutive minutes of zeros were cleaned, because it was considered that ActiGraph was not being worn (39) and the zeros were changed to missing data.

\section{Academic Performance}

Academic performance was assessed in order to describe the different factors that may influence the success of pupils in school. AP was presented through average grades, calculated from all grades obtained during the whole school year 2014/15 from following school subjects: Mathematics, Slovene language, English language, and PE GPA. GPA was calculated as arithmetic mean grade of average grades from all subjects in that school year.

\section{Data Collection}

The data for the present study were collected at the primary school Ivana Groharja in Škofja Loka. PF data from the school's SLOfit database were evaluated, and PA was measured from Wednesday to Sunday in June 2014 using the ActiGraph GT3X accelerometer. AP was evaluated based on the school documentation provided. In addition, data on additional engagement in sport and the mode of commuting to school were assessed from PA diaries.

\section{Data Processing and Statistical Analysis}

All statistics were made in Microsoft Excel 2007 and IBM SPSS, 20.0. Microsoft Excel 2007 was used for removing the artifacts, counts $>16.000$, constant values $\geq 0$, and sequences of zeroes, where the sequence was 20 or more zeroes. PA data were processed with the Actilife software (standardized for accelerometer ActiGraph), following the 70/80 rule (38) and non-wear time within a day (40). Testing for distributions of the normality was checked visually (histogram) and with the Kolmogorov-Smirnov test using IBM SPSS Statistics 25.0. Descriptive statistics were calculated for all variables (mainly as mean and standard deviation). Associations between derived estimates of grades, PF, and counts from accelerometer data were computed using the Spearman's correlation. The difference between weekday and weekend PA was assessed using the paired sample $t$-test. The effect size was determined using the Cohen's d. The Chi-square test was used to investigate the correlations between engaging in sport activities and PA and between modes of commuting to school and PA. 


\section{RESULTS}

Table 1 shows the evaluated results of the PF of the pupils. It can be seen that the CV\% value for the Bent Arm Hang test is very high, which indicates the high dispersion of a frequency distribution.

Figure 1 shows that the daily measured PA of pupils reached $536 \pm 240$ counts/min. The average PA on the weekend days was lower than PA on the school days (516 and 557, respectively). The variance of weekend PA counts was \pm 328 , indicating significant differences in weekend PA among primary school pupils. The standard deviation of PA counts on the weekdays was \pm 199 , indicating a uniform PA pattern of female pupils during the school hours, as the dispersion of the PA counts is lower than

TABLE 1 | Descriptive statistics of the physical fitness of the pupils.

\begin{tabular}{lccccc}
\hline PF tests & Mean & SD & Min & Max & CV\% \\
\hline Taping (n) & 42.3 & 2.8 & 37.0 & 47.0 & 6.7 \\
Long jump (cm) & 178.8 & 27.5 & 130.0 & 230.0 & 15.4 \\
Polygon backwards (s) & 13.5 & 8.7 & 8.4 & 45.0 & 6.5 \\
Sit-ups (n) & 49.3 & 10.8 & 30.0 & 63.0 & 21.9 \\
Stand and reach (cm) & 49.0 & 6.6 & 35.0 & 60.0 & 13.6 \\
Bent arm hang (s) & 51.7 & 36.1 & 3.0 & 120.0 & 69.8 \\
Sprint 60 m (s) & 9.9 & 1.0 & 8.6 & 12.2 & 9.9 \\
Running 600 m (s) & 150.8 & 33.5 & 109.0 & 215.0 & 22.2 \\
\hline
\end{tabular}

Mean, averaged value; SD, standard deviation; Min, minimum value; Max, maximum value; $\mathrm{CV} \%$, coefficient of variation. on weekends. Regardless of higher PA counts during weekdays, the paired sample $t$-test showed no significant differences in PA counts during weekdays and weekends.

Table 2 shows the prevalence of children taking part in additional sports during the day (in minutes/day) and the way they commute (in minutes/day). The Chi-square test showed no significant correlations between engaging in sport and type of PA and between the modes of commuting and the types of PA ( $p=$ 0.42 and $p=0.12$, respectively).

As can be seen from the percentage distributions, the children who are engaging in additional sport or PA are reaching recommendations for PA (high PA). Similarly, the children who commuted actively are spending the most time in PA actively. The average grades were calculated for the school year 2014/2015. The calculation of the average grade took into account all grades of an individual school subject in the 2014/15 school

TABLE 2 | Sports participation and commuting of included participants.

\begin{tabular}{llcccc}
\hline PA or sports in min/day & Very low PA & Low PA & Normal PA & High PA \\
\hline $\begin{array}{l}\text { Engaging in } \\
\text { sport }\end{array}$ & $\begin{array}{l}\text { Additional } \\
\text { sport }\end{array}$ & $12,5 \%$ & $25,0 \%$ & $12,5 \%$ & $50,0 \%$ \\
& $\begin{array}{l}\text { Without } \\
\text { additional }\end{array}$ & $50,0 \%$ & $12,5 \%$ & $12,5 \%$ & $25,0 \%$ \\
& sport & & & & \\
\multirow{2}{*}{ Commuting } & Active & $0,0 \%$ & $28,6 \%$ & $14,3 \%$ & $57,1 \%$ \\
& Driven & $55,6 \%$ & $11,1 \%$ & $11,1 \%$ & $22,2 \%$ \\
\hline
\end{tabular}

Very low PA ( $<30$ min of PA/day); low PA ( $>30$ min PAdday <450 min PA/day); normal PA (>45 min PA/day <60 min PA/day); high PA (>60 min PA/day).

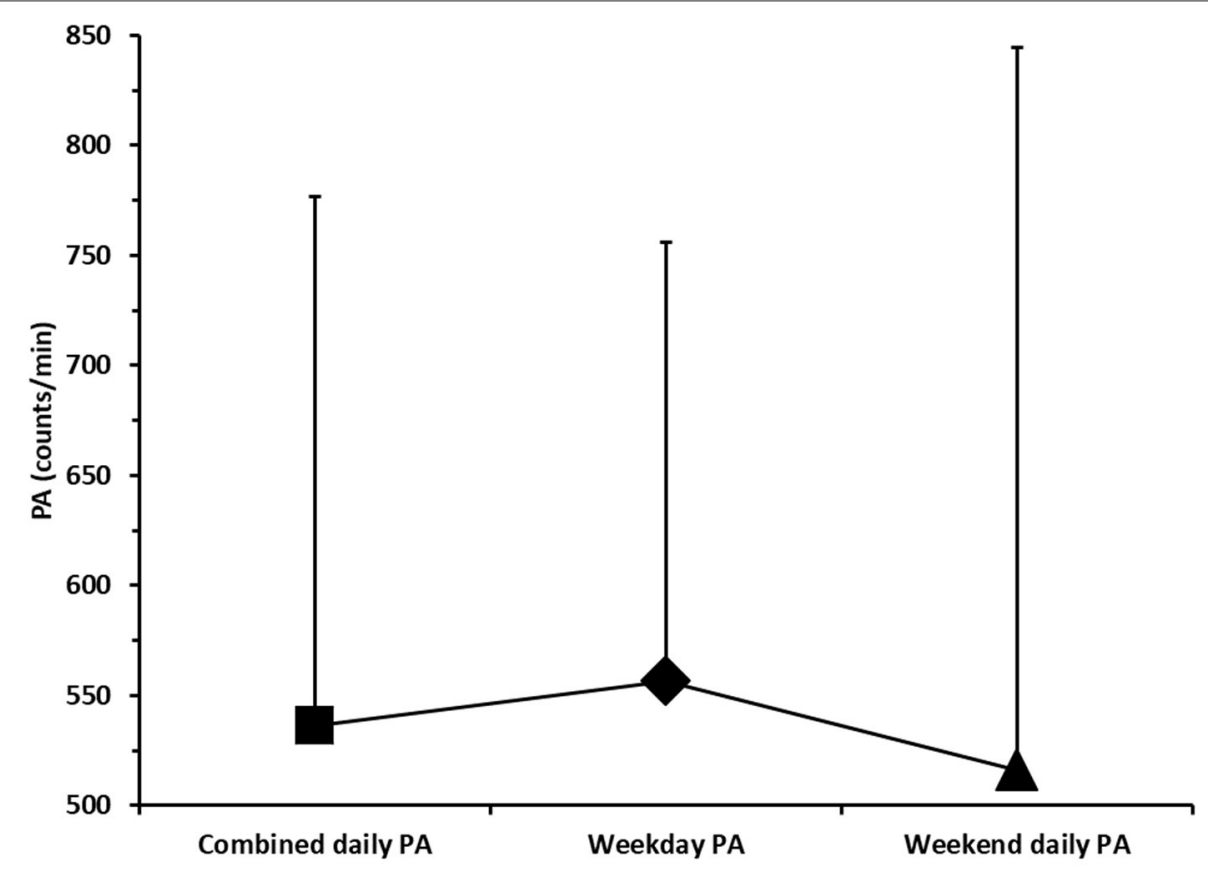

FIGURE 1 | Combined physical activity (PA), weekday PA, and weekend PA of adolescent school girls. 
year. All grades and descriptive statistics on the AP are shown in Table 3.

Correlations between PF and AP and between PA and AP were identified using the Spearman's correlation analysis. Figure 2 shows the above-mentioned correlations for 20 school girls.

Note that the correlation coefficients for the tests Polygon backward, Sprint $60 \mathrm{~m}$ and Running $600 \mathrm{~m}$ were negative. Nevertheless, we presented them as positive values, since lower values of the above-mentioned tests represented better results and, therefore, correlation was essentially positive. At first glance, it is noticeable that the PE grade shows the highest overall correlations with the results of the PF test battery $(r=0.53-$ $0.95)$ at the significance level 0.01 . Nevertheless, correlations

TABLE 3 | Descriptive statistics for academic performance.

\begin{tabular}{lcc}
\hline Subject & Mean grade & SD \\
\hline Mathematics & 3.44 & 0.93 \\
Slovene language & 3.78 & 0.80 \\
English language & 3.34 & 1.02 \\
Second language & 3.56 & 0.85 \\
Physical Education & 4.25 & 0.70 \\
GPA & 4.10 & 0.64
\end{tabular}

$A P$, academic performance; Mean grade, average grade throughout the school year for selected subject or GPA; SD, standard deviation; GPA, grade point average. surprisingly decrease for the combined daily PA $(r=0.45)$, especially the weekend daily PA $(r=0.28)$. The situation is somewhat different for GPA, where the correlations with PF were mostly moderate $(r=0.43-0.64$; with the exception of Taping, where $r=0.26$ ), while they were moderate to high for PA $(r=0.59-0.87)$. A similar trend was observed for grades in mathematics, native, and foreign languages. The overall lowest correlations with the PF results and one of the highest with PA were found for the grades of the native language.

\section{DISCUSSION}

The results revealed that the girls were more physically active during the weekdays and less active at the weekend (557 vs. 516 counts/min). Despite statistically insignificant differences, the dispersion of results around the average PA during weekdays was lower compared to weekends, indicating more consistent patterns of PA among schoolchildren during the school days. The relatively large dispersion around the average PA could be explained by the relatively small sample size. It can also be explained by the large differences between the minimum and maximum values of the results obtained in a few tests. For example, the worst result in the Bent Arm Hang was only $3 \mathrm{~s}$, which indicates that some of the girls had a large deficit in the upper body strength. In addition, $45 \mathrm{~s}$ in Polygon Backward indicates very poor coordination skills.




Compared to many other countries, the Republic of Slovenia has a respectable $\mathrm{PE}$ curriculum compared to many other countries $(29,41)$. PE in the Republic of Slovenia is a standardized and compulsory subject in all primary and secondary schools (41), which is also confirmed when comparing overall activity minutes during weekdays and weekends. According to the results of the present study and following other Slovenian studies (4143 ), we can say that the Slovenian primary schoolchildren are physically more active on weekdays, what is also in concordance with other studies $(44,45)$. In fact, all schools in the Slovenia offer their pupils the opportunity to engage in PA and the majority of Slovenian pupils can be physically active for up to $51 \mathrm{~min}$ a day during the school day (41). The decrease at weekends is largely due to a decrease in the intensity of light intensity bouts (44) and the lack of the structured school environment at weekends determine the different PA levels and patterns, which is particularly noticeable among girls (46). As we have included only girls in the present study, the actual PA counts of schoolchildren could be different, probably significantly higher for boys compared to girls, as found in other studies on the Slovenian schoolchildren $(42,47,48)$.

Attention-grabbing results were found regarding the correlations between PF, PA, and AP. As expected, the correlation analysis revealed that the pupils with the highest PE grades had the highest level of PF. This could be explained, for example, by knowing that school PE programs routinely allow children to exercise their abdominal muscles and, therefore, a high correlation between PF score and PE grade could be expected. Remarkably, moderate to high correlations were found between the results of PF and GPA, mathematics, native, and foreign languages grades. This is in-line with the previous studies $(49,50)$.

Surprisingly, however, the same pupils with high grades had a low level of PA. Nevertheless, the trend was the same as for the others-they were more active on weekdays than at weekends. We can only discuss these findings. One reason for this could be that some of the girls took off the accelerometer during the training sessions and games, so this influenced the lower correlation. However, this assumption is probably not true, since the Chi-square test showed that the additional engagement in sports was not a significant factor for the average PA during the day $(p=0.12)$. However, although there was no significant correlation. Table 2 shows that such results could be explained by the mode of commuting to school as an important factor. It has been shown that it is very important to separate commuting from home to school and vice versa, as it turned out that children who actively commute from school to home have higher VO2 max (51). A possible explanation could be playing in the playgrounds on the way of home and spending more time in the highintensity PA. Inactive commuting to school in the morning is often associated with the parental convenience of dropping a child off at school on the way to work, and not necessarily with reservations about the active commuting or an active lifestyle. We speculate that the Chi-square test results would be significant if we had these data separated.

The results should be interpreted with caution and cannot be presented as if the increased PF or PA caused an improved
AP or vice versa. Many questions arose after the completion of the present study and several new topics opened up, such as the question of how parental education affects the duration of PA and AP of the children and the influence of the place of residence on AP of the children. Self-reported results should be carefully interpreted in terms of the validity and reliability (52) of the measured data, and an objective measurement of PA should be considered to ensure the accuracy of the results. All questions raised in the present study should be considered and analyzed in future studies.

\section{Strengths and Limitations}

The results of this study indicate that there is a significant correlation between $\mathrm{AP}, \mathrm{PA}$, and $\mathrm{PF}$ for certain outcome measures. However, before outlining the benefits of PA and PF on AP, it is important to note that many factors influence AP. These include socio-economic status, parental involvement, PA, and participation in sport and other demographic factors such as place of residence.

There are methodological limitations to be considered in the current research: (i) the study was conducted with a relatively small sample size $(n=20)$ of schoolchildren; in order to generalize the results to larger groups, the study should have included more participants. Moreover, all the girls were picked from an extracurricular activity called "Healthy lifestyle," therefore, a potential bias in sample might occur; (ii) the children knew they had been monitored (53), therefore, we did not measure their habitual PA and the results cannot be generalized as a completely realistic measure for PA; (iii) accelerometers are not able to detect the static exercises (54), and the devices might underestimate PA in total; (iv) high device costs and an insufficient number of accelerometers did not allow the measurement of all girls in the same time interval, so that there might be differences in the duration of PA due to different weather conditions; (v) AP was evaluated based on a mathematical grade, Slovenian language grade, a natural science grade, and GPA. AP grades were based on the assessments of the school teachers, therefore, a possible "rater bias" might have been introduced so that the results can only be generalized to those instruments that assess AP; (vi) there was a lack of separate data on the mode of commuting from home to school and vice versa.

\section{CONCLUSIONS}

The purpose of this study was to investigate the level of PF, objectively measured PA of Slovenian girls, and the relationship between PF, PA, and their AP. The results showed that the girls were more physically active during the weekdays and less active at the weekends. As expected, the correlation analysis showed that the pupils with the highest PE grades had the highest level of PF but had surprisingly low to moderate correlations with the level of PA. The frequency of the PA type in relation to the mode of commuting to school showed that such results could be explained by the mode of commuting to school as an important factor. Based on our previous research, it is assumed that the main factor is commuting from school to 
home. In addition, moderate to high correlations were found between the results of PF and GPA, mathematics, native, and foreign languages grades. The highest correlation was found between GPA and the combined daily PA. It has been shown that the PE system could influence the future PA and lifestyle of schoolchildren (55) and consequently health status and PF in adulthood.

\section{DATA AVAILABILITY STATEMENT}

The raw data supporting the conclusions of this article will be made available by the authors, without undue reservation.

\section{ETHICS STATEMENT}

The studies involving human participants were reviewed and approved by National Medical Ethics Committee (ID $138 / 05 / 13)$. Written informed consent to participate in this study was provided by the participants' legal guardian/next of kin.

\section{REFERENCES}

1. Caspersen CJ, Powell KE, Christenson GM. Physical activity, exercise, and physical fitness: definitions and distinctions for health-related research. Public Health Rep. (1985) 100:126-31.

2. Fletcher GF, Balady G, Blair SN, Blumenthal J, Caspersen C, Chaitman B, et al. Statement on exercise: benefits and recommendations for physical activity programs for all Americans: a statement for health professionals by the Committee on Exercise and Cardiac Rehabilitation of the Council on Clinical Cardiology, American Heart Associ. Circulation. (1996) 94:857-62. doi: 10.1161/01.CIR.94.4.857

3. Powell KE, Pratt M. Physical activity and health. BMJ. (1996) 313:126-7. doi: 10.1136/bmj.313.7050.126

4. Bull FC, Bellew B, Schöppe S, Bauman AE. Developments in National Physical Activity Policy: an international review and recommendations towards better practice. J Sci Med Sport. (2004) 7:93-104. doi: 10.1016/S1440-2440(04)80283-4

5. Swift DL, Lavie CJ, Johannsen NM, Arena R, Earnest CP, O'Keefe JH, et al. Physical activity, cardiorespiratory fitness, and exercise training in primary and secondary coronary prevention. Circ J. (2013) 77:281-92. doi: 10.1253/circj.CJ-13-0007

6. Drenowatz C, Prasad VK, Hand GA, Shook RP, Blair SN. Effects of moderate and vigorous physical activity on fitness and body composition. J Behav Med. (2016) 39:624-32. doi: 10.1007/s10865-016-9740-z

7. Janssen I, LeBlanc AG. Systematic review of the health benefits of physical activity and fitness in school-aged children and youth. Int J Behav Nutr Phys Act. (2010) 7:40. doi: 10.1186/1479-5868-7-40

8. Biddle SJH, Asare M. Physical activity and mental health in children and adolescenats: a review of reviews. Br J Sports Med, bjsports. (2011) 45:886-95. doi: 10.1136/bjsports-2011-090185

9. Singh AS, Saliasi E, Van Den Berg V, Uijtdewilligen L, De Groot RHM, Jolles J, et al. Effects of physical activity interventions on cognitive and academic performance in children and adolescents: a novel combination of a systematic review and recommendations from an expert panel. Br J Sport Med. (2019) 53:640-7. doi: 10.1136/bjsports-2017-098136

10. Fedewa AL, Ahn S. The effects of physical activity and physical fitness on children's achievement and cognitive outcomes: a meta-analysis. Res Q Exerc Sport. (2011) 82:521-35. doi: 10.1080/02701367.2011.10599785

11. Castelli DM, Hillman CH, Buck SM, Erwin HE. Physical fitness and academic achievement in third-and fifth-grade students. J Sport Exerc Psychol. (2007) 29:239-52. doi: 10.1123/jsep.29.2.239

\section{AUTHOR CONTRIBUTIONS}

VS and SĐ conceptualized the study design, recruited subjects into the study, and analyzed and interpreted the data. VZ conducted the research. VS, ŠB, SĐ, and VZ drafted and reviewed the manuscript. All authors have read and approved the final version of the manuscript.

\section{FUNDING}

This research was funded by the Slovenian Research Agency within the Research project Bio-psycho-social context of kinesiology No. P5-0142 and University Medical Centre tertiary grant TP20210071.

\section{ACKNOWLEDGMENTS}

Dr. Shawnda A. Morrison was kindly acknowledged for reading the manuscript and giving helpful suggestions in the data collection, mining the data, and writing the paper.

12. Trudeau F, Shephard RJ. Physical education, school physical activity, school sports and academic performance. Int J Behav Nutr Phys Act. (2008) 5:10. doi: $10.1186 / 1479-5868-5-10$

13. An J, Meaney KS. Inclusion practices in elementary physical education: a social-cognitive perspective. Int J Disabil, Dev Educ. (2015) 62:143-57. doi: 10.1080/1034912X.2014.998176

14. Bailey R, Armour K, Kirk D, Jess M, Pickup I, Sandford R, et al. The educational benefits claimed for physical education and school sport: an academic review. Res Pap Educ. (2009) 24:1-27. doi: 10.1080/02671520701809817

15. Erickson KI, Voss MW, Prakash RS, Basak C, Szabo A, Chaddock L, et al. Exercise training increases size of hippocampus and improves memory. Proc Natl Acad Sci U S A. (2011) 108:3017-22. doi: 10.1073/pnas.1015950108

16. Kleim JA, Cooper NR, VandenBerg PM. Exercise induces angiogenesis but does not alter movement representations within rat motor cortex. Brain Res. (2002) 934:1-6. doi: 10.1016/S0006-8993(02)02239-4

17. Hillman $\mathrm{CH}$, Erickson KI, Kramer AF. Be smart, exercise your heart: exercise effects on brain and cognition. Nat Rev Neurosci. (2008) 9:58. doi: $10.1038 / \mathrm{nrn} 2298$

18. Singh A, Uijtdewilligen L, Twisk J, van Mechelen W, Chinapaw M. Physical activity and student performance at school: a systematic review of the literature including a methodological quality assessment. Arch Pediatr Adolesc Med. (2012) 166:49-55. doi: 10.1001/archpediatrics.2011.716

19. Daly-Smith AJ, Zwolinsky S, McKenna J, Tomporowski PD, Defeyter MA, Manley A. Systematic review of acute physically active learning and classroom movement breaks on children's physical activity, cognition, academic performance and classroom behaviour: understanding critical design features. BMJ Open Sport Exerc Med. (2018) 4:1-16. doi: 10.1136/bmjsem-2018-0 00341

20. Sember V, Jurak G, Kovač M, Morrison SA, Starc G. Children's physical activity, academic performance and cognitive functioning: a systematic review and meta-analysis. Front Public Heal. (2020) 8:307. doi: 10.3389/fpubh.2020.00307

21. Sember V, KriŽaj J. Validity of useful assessment strategies of physical activity in adolescents. Kinesiol. Slov. (2019) 25:44-51.

22. Watson A, Timperio A, Brown H, Best K, Hesketh KD. Effect of classroombased physical activity interventions on academic and physical activity outcomes: a systematic review and meta-analysis. Int J Behav Nutr Phys Act. (2017) 14:114. doi: 10.1186/s12966-017-0569-9

23. Fedewa AL, Fettrow E, Erwin H, Ahn S, Farook M. Academic-based and aerobic-only movement breaks: Are there differential effects on 
physical activity and achievement? Res. Q Exerc Sport. (2018) 89:153-63. doi: 10.1080/02701367.2018.1431602

24. Glapa A, Grzesiak J, Laudanska-Krzeminska I, Chin M-K, Edginton C, Mok M, et al. The impact of brain breaks classroom-based physical activities on attitudes toward physical activity in polish school children in third to fifth grade. Int J Environ Res Public Health. (2018) 15:368. doi: $10.3390 /$ ijerph 15020368

25. Ploughman M. Exercise is brain food: the effects of physical activity on cognitive function. Dev Neurorehabil. (2008) 11:236-40. doi: 10.1080/17518420801997007

26. Donnelly JE, Hillman CH, Castelli D, Etnier JL, Lee S, Tomporowski P, et al. Physical activity, fitness, cognitive function, and academic achievement in children: a systematic review. Med Sci Sports Exerc. (2016) 48:1197. doi: 10.1249/MSS.0000000000000901

27. Goh TL, Hannon J, Webster C, Podlog L, Newton M. Effects of a TAKE 10 ! classroom-based physical activity intervention on third- to fifthgrade children's on-task behavior. J Phys Act Health. (2016) 13:712-8. doi: 10.1123/jpah.2015-0238

28. Tremblay MS, Barnes JD, González SA, Katzmarzyk PT, Onywera VO, Reilly JJ, et al. Global matrix 2.0: report card grades on the physical activity of children and youth comparing 38 countries. J Phys Act Health. (2016) 13:34366. doi: 10.1123/jpah.2016-0594

29. Sember V, Morrison SA, Jurak G, Kovač M, Golobič M, Pavletić SamardŽija P, et al. Results from Slovenia's 2018 report card on physical activity for children and youth. J Phys Act Heal. (2018) 15:S404-5. doi: 10.1123/jpah.20180542

30. Matejek C, Starc G. The relationship between children's physical fitness and gender, age and environmental factors. Ann Kinesiol. (2013) 4:17-30.

31. Strnisa K, Planinsec J. Gibalna dejavnost otrok z vidika socialno-ekonomskih razseznosti. Rev za Elem Izobr. (2014) 7:99.

32. Prince S, Adamo K, Hamel M, Hardt J, Gorber S, Tremblay M. A comparison of direct versus self-report measures for assessing physical activity in adults: a systematic review. Int J Behav Nutr Phys Act. (2008) 5:56. doi: 10.1186/1479-5868-5-56

33. Jurak G, Cooper A, Leskosek B, Kovac M. Long-term effects of 4-year longitudinal school-based physical activity intervention on the physical fitness of children and youth during 7-year follow-up assessment. Cent Eur J Public Health. (2013) 21:190. doi: 10.21101/cejph.a3823

34. Volmut $T$, Pišot $R$, Šimunič B. Objectively measured physical activity in children aged from 5 to 8 years / Objektivno Izmerjena Gibalna Aktivnost Od Pet- Do Osemletnih Otrok. Slov J Public Heal. (2013) 52:9-18. doi: 10.2478/sjph-2013-0002

35. Cain KL, Sallis JF, Conway TL, Van Dyck D, Calhoon L. Using accelerometers in youth physical activity studies: a review of methods. J Phys Act Heal. (2013) 10:437-50. doi: 10.1123/jpah.10.3.437

36. Masse LC, Fuemmeler BF, Anderson CB, Matthews CE, Trost SG, Catellier DJ, et al. Accelerometer data reduction: a comparison of four reduction algorithms on select outcome variables. Med Sci Sports Exerc. (2005) 37:S54454. doi: 10.1249/01.mss.0000185674.09066.8a

37. Schmidt MD, Freedson PS, Chasan-Taber L. Estimating physical activity using the CSA accelerometer and a physical activity log. Med Sci Sport Exerc. (2003) 35:1605-11. doi: 10.1249/01.MSS.0000084421.97661.17

38. Catellier DJ, Hannan PJ, Murray DM, Addy CL, Conway TL, Yang $\mathrm{S}$, et al. Imputation of missing data when measuring physical activity by accelerometry. Med Sci Sports Exerc. (2005) 37:S555. doi: 10.1249/01.mss.0000185651.59486.4e

39. Evenson KR, Catellier DJ, Gill K, Ondrak KS, McMurray RG. Calibration of two objective measures of physical activity for children. J Sports Sci. (2008) 26:1557-65. doi: 10.1080/02640410802334196

40. Troiano RP, Berrigan D, Dodd KW, Mâsse LC, Tilert T, Mcdowell M. Physical activity in the United States measured by accelerometer. Med Sci Sports Exerc. (2008) 40:181-8. doi: 10.1249/mss.0b013e31815a51b3

41. Sember V, Starc G, Jurak G, Golobič M, Kovač M, SamardŽija PP, et al. Results from the republic of Slovenias 2016 report card on physical activity for children and youth. J Phys Act Heal. (2016) 13:S256-64. doi: 10.1123/jpah.2016-0294
42. Jurak G, Sorić M, Starc G, Kovač M, Mišigoj-Duraković M, Borer K, et al. School day and weekend patterns of physical activity in urban 11-yearolds: A cross-cultural comparison. Am. J. Hum. Biol. (2015) 27:192-200. doi: $10.1002 / a j h b .22637$

43. Sember V, Morrison SA, Jurak G, Kovac M, Starc G. Differences in physical activity and academic performance between urban and rural schoolchildren in Slovenia. Montenegrin J Sport Sci Med. (2018) 7:67-72. doi: $10.26773 / \mathrm{mjssm} .180309$

44. Rowlands AV, Pilgrim EL, Eston RG. Patterns of habitual activity across weekdays and weekend days in 9-11-year-old children. Prev Med (Baltim). (2008) 46:317-24. doi: 10.1016/j.ypmed.2007.11.004

45. Fairclough SJ, Boddy LM, Mackintosh KA, Valencia-Peris A, RamirezRico E. Weekday and weekend sedentary time and physical activity in differentially active children. J Sci Med Sport. (2015) 18:444-9. doi: 10.1016/j.jsams.2014.06.005

46. Mota J, Santos P, Guerra S, Ribeiro JC, Duarte JA. Patterns of daily physical activity during school days in children and adolescents. Am J Hum Biol. (2003) 15:547-53. doi: 10.1002/ajhb.10163

47. Zurc J, Pišot R, Strojnik V. Gender Differences in Motor Performance in 5-6 year old children. Kinesiol Slov. (2005) 11:90-104.

48. Pišot R, Zurc J. Gibalna/športna aktivnost pri učencih in učenkah drugega vzgojno-izobraževalnega obdobja osnovne šole. Pedagoška Obzorja. (2004) 19:28-37.

49. Van Dusen DP, Kelder SH, Kohl III HW, Ranjit N, Perry CL. (2011). Associations of physical fitness and academic performance among schoolchildren. J. Sch. Health 81, 733-740. doi: 10.1111/j.1746-1561.2011.00652.x

50. Coe DP, Peterson T, Blair C, Schutten MC, Peddie H. Physical fitness, academic achievement, and socioeconomic status in school-aged youth. J Sch Health. (2013) 83:500-7. doi: 10.1111/josh.12058

51. Sember V, Starc G, Kovač M, Golubič M, Jurak G. Spremenimo slabo prakso》 dostavljanja «otrok v šolo. Sport Rev. Za Teor. Prakt. Vprasanja Sport. (2019) 67:193-8.

52. Shephard RJ. Limits to the measurement of habitual physical activity by questionnaires. $\mathrm{Br} J$ Sports Med. (2003) 37:197-206. doi: 10.1136/bjsm.37.3.197

53. Dencker M, Andersen LB. Accelerometer-measured daily physical activity related to aerobic fitness in children and adolescents. J Sports Sci. (2011) 29:887-95. doi: 10.1080/02640414.2011.578148

54. Bouten CV, Sauren AA, Verduin M, Janssen JD. Effects of placement and orientation of body-fixed accelerometers on the assessment of energy expenditure during walking. Med Biol Eng Comput. (1997) 35:50-6. doi: 10.1007/BF02510392

55. Emeljanovas A, Malinauskas R, Valentine I, Hardman K. The relationship between the assessment system in physical education in the former soviet state of Lithuania and physical activity levels of adults. Kinesiol Int J Fundam Appl Kinesiol. (2015) 47:242-52.

Conflict of Interest: The authors declare that the research was conducted in the absence of any commercial or financial relationships that could be construed as a potential conflict of interest.

Publisher's Note: All claims expressed in this article are solely those of the authors and do not necessarily represent those of their affiliated organizations, or those of the publisher, the editors and the reviewers. Any product that may be evaluated in this article, or claim that may be made by its manufacturer, is not guaranteed or endorsed by the publisher.

Copyright () 2021 Đurić, Bogataj, Zovko and Sember. This is an open-access article distributed under the terms of the Creative Commons Attribution License (CC BY). The use, distribution or reproduction in other forums is permitted, provided the original author(s) and the copyright owner(s) are credited and that the original publication in this journal is cited, in accordance with accepted academic practice. No use, distribution or reproduction is permitted which does not comply with these terms. 